REVIEW

\title{
A META-ANALYSIS OF SOCIO-DEMOGRAPHIC FACTORS PREDICTING BIRTH IN HEALTH FACILITY
}

\author{
Yifru Berhan", Asres Berhan²
}

\begin{abstract}
BACKGROUND: The low proportion of health facility delivery in developing countries is one of the main challenges in achieving the Millennium Development Goal of a global reduction of maternal deaths by $75 \%$ by 2015. There are several primary studies which identified socio-demographic and other predictors of birth in health facility. However, there are no efforts to synthesis the findings of these studies. The objective of this meta-analysis was to determine the strength of the association of birth in the health facility with selected sociodemographic factors.

METHODS: A meta-analysis of Mantel-Haenszel odds ratios was conducted by including 24 articles which were reported between 2000 and 2013 from developing countries. A computer-based search was done from MEDLINE, African Journals Online, Google Scholar and HINARI databases. Included studies did compare the women's' health facility delivery in relation to their selected socio-demographic characteristics.

RESULTS: The pooled analysis demonstrated association of health facility delivery with living in urban areas $(O R=9.8)$, secondary and above educational level of the parents $(O R=5.0)$, middle to high wealth status $(O R=2.3)$ and first time pregnancy $(O R=2.8)$. The risk of delivering outside the health facility was not significantly associated with maternal age (teenage vs 20 years and above) and marital status. The distance of pregnant women's residence from the health facility was found to have an inverse relation to the proportion of health facility delivery.

CONCLUSION: Although the present meta-analysis identified several variables which were associated with an increase in health facility delivery, the most important predictor of birth in the health facility amenable to intervention is educational status of the parents to be. Therefore, formal and informal education to women and family members on the importance of health facility delivery needs to be strengthened. Improving the wealth status of the population across the world may not be achieved soon, but should be in the long-term strategy to increase the birth rate in the health facility.

KEYWORDS: community based studies, developing countries, health facility delivery, meta-analysis, socio-demographic variables
\end{abstract}

DOI: http://dx.doi.org/10.4314/ejhs.v24i1.8S

\section{INTRODUCTION}

While almost all births in high income countries occur with the help of skilled birth attendants. More than half of all births (53\%) in low income countries, however, still take place without the help of skilled birth attendants (1). Similarly, the mean proportions of at least four antenatal care visits in low income countries were estimated to be more than two and half times lower than those of the high income countries (96\% vs 37\%) (1). Probably, related to this low utilization of skilled attendants during pregnancy and delivery, more than $99 \%$ of maternal and perinatal deaths in the last decade occurred in developing

\footnotetext{
${ }^{1}$ Hawassa University, College of Medicine and Health Sciences, Department of Gynecology-Obstetrics

${ }^{2}$ Hawassa University, College of Medicine and Health Sciences, Department of Pharmacology

Corresponding Author: Yifru Berhan, Email: yifrub@gmail.com
} 
countries $(2,3)$. It was also noted that the low proportion of skilled health personnel attended delivery in developing countries is one of the main challenges to achieve the Millennium Development Goal (MDG) of a global reduction of maternal deaths by $75 \%$ by $2015(4,5)$.

It has been stated that the reasons for the low utilization of skilled attendants during delivery by the women in developing countries are complex and multidimensional. Ineffective health decision making at the family level, the influence of traditional healers, low level of education, inadequate transportation facilities and insecurity at night, high cost of health services, and inhospitable health service providers among others were attributed to the low health facility delivery in developing countries (6-10). The long tradition of home delivery attended by a traditional birth attendant might have also a strong influence on intention to give birth in a health facility.

There are several primary researches that assessed various factors associated with the birth in the health facility or at home in developing countries in the last decade (11-34). However, there was no meta-analysis conducted to examine the pooled effect of the various factors on birth in the health facility. There were also several inconsistent findings with regard to association of health facility delivery with the mothers' age, parity, level of parents' education, area of residence, marital and wealth status $(7,35)$.

Thus, although all factors could not be included, the objective of this meta-analysis was to determine the strength of the association of birth in the health facility with the mother's age, area of residence, parents' level of education, wealth and marital status and parity.

\section{METHODS}

\section{Search strategy}

A computer based literature search was conducted by both authors (YB, $\mathrm{AB}$ ) in the databases of HINARI, Medline, African Journals Online, Google Scholar, and the Cochrane Library. The literature search was further strengthened by searching the websites of major publishers (Elsevier Science-Science Direct, Nature Publishing Group, Oxford University Press, PsycARTICLES, Science, and Wiley-Blackwell) via HINARI and by searching the reference lists of retrieved articles.

During literature search, the following preselected search terms were alternatively combined with health facility delivery using the Boolean logic (AND, OR, and NOT): maternal age, maternal education level, husband/partner/paternal educational level, distance from a health facility, antenatal care, residence, marital status, wealth status, and parity.

\section{Inclusion criteria and study selection}

The inclusion criteria for this meta-analysis were: (1) studies that assessed place of delivery in developing countries, (2) studies that were written in English, (3) studies published between 2000 and 2013 and (4) studies with cross sectional or case control design. Study selection was conducted by both authors independently. Firstly, the abstracts of all the retrieved articles were reviewed and grouped as "eligible for full document review" and "ineligible for full document review". Then, the final decision of either to include studies in the meta-analysis or to exclude them was reached by reviewing in detail the whole contents of the studies that were grouped as "eligible for full document review". When there was disagreement between the authors, it was resolved by discussion and by rereviewing the specific articles jointly.

\section{Data extraction}

With a similar data extraction template, data extraction was performed by both authors independently using Excel Spreadsheets. Information was abstracted for the following variables: name of the first author, year of publication, mothers' age, mothers' education level, wealth status, residence, marital status, parity, and fathers' education level.

\section{Data synthesis and statistical analysis}

To make fit for meta-analysis software, all the selected variables were dichotomized purposely: age as < 20 years vs 20 years and above; residence as urban vs rural; educational level as primary or no education vs secondary and above; wealth status as low or lowest vs middle to highest; marital status as married vs unmarried; and parity as primigravida vs multiparous. Studies that 
categorized the wealth status data like MEASURE DHS standard (lowest, low, middle, high and highest) were included. In the correlation analysis, equivalent/average estimation was made in $\mathrm{km}$ (for $50 \mathrm{~km}$ distance, one hour travel) for pregnant women's residence distance reported in hours for vehicle travel.

The proportion of births in the health facility was assessed using the random effects model. Odds ratios (OR) and the $95 \%$ CIs were computed with Mantel-Haenszel method. When the 95\% CI did not include number 1 , it was considered as statistically significant. The consistency of the included studies was evaluated by heterogeneity testing, chi-squared test (Cochran $\mathrm{Q}$ test) and $\mathrm{I}^{2}$ statistics. When the value of $\mathrm{I}^{2}$ was equal to or greater than $50 \%$, the studies included in the analysis were considered as significantly inconsistent. Furthermore, sensitivity analysis (leave one study alternately during analysis) was conducted to assess the stability of the pooled values to outliers and the impact of individual studies. All the statistical analyses were carried out using Review Manager (RevMan) Version 5.1 software.

\section{RESULTS}

\section{Description of the studies}

As shown in Figure 1, the literature search for the selected search terms initially identified 7,522 citations. Following a review of the titles for their relevance for this meta-analysis, 7213 were excluded from retrieval. Out of 309 retrieved articles, 201 were excluded after reviewing their abstracts. The full document of 108 articles was reviewed and finally 24 articles were selected for this meta-analysis (11-34). Of the included studies, 16 were published between year 2011 and 2013; the majority were community based studies; and 12 were reported from Ethiopia (Table 1). Most of the included studies employed cross sectional study design. Significant heterogeneity was observed among the selected studies. But, the sensitivity analyses did not bring significant change in the overall odds ratios.

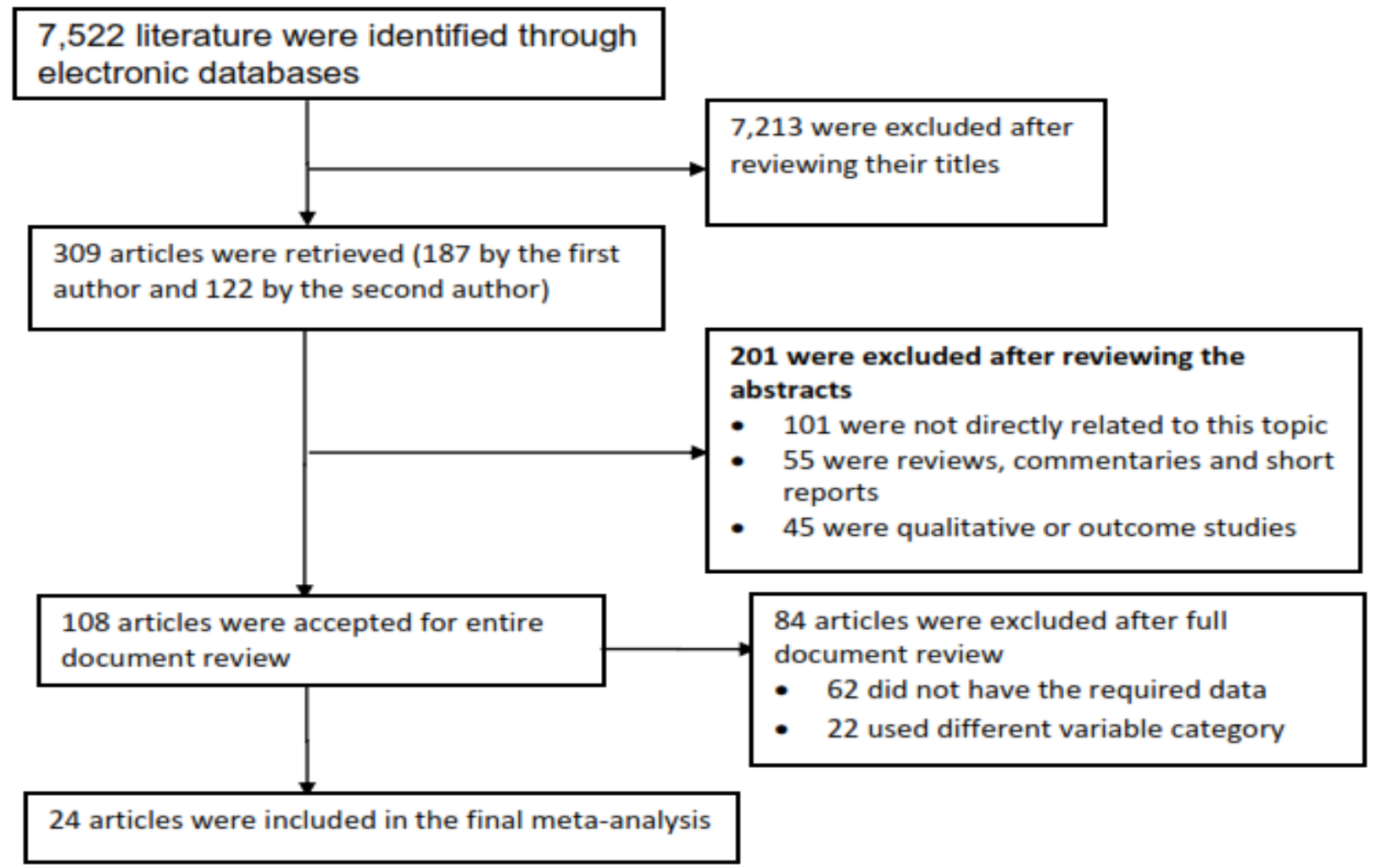

Figure 1: Flow diagram showing included studies selection 
Table 1: General characteristics of studies included in this meta-analysis

\begin{tabular}{|l|l|l|l|l|}
\hline Author & Year & Country & Study design & Sample size \\
\hline Wado YD et al (12) & 2013 & Ethiopia & Community based survey & 1370 \\
\hline Shiferaw S et al (13) & 2013 & Ethiopia & Community based cross sectional & 909 \\
\hline Tsegay Y et al (14) & 2013 & Ethiopia & Community based cross sectional & 1113 \\
\hline Mengesha ZB et al (15) & 2013 & Ethiopia & $\begin{array}{l}\text { Community based nested case } \\
\text { control study }\end{array}$ & 1065 \\
\hline Worku AG et al (16) & 2013 & Ethiopia & Population based survey & 1668 \\
\hline Nanjala M et al (17) & 2012 & Kenya & Community based cross sectional & 380 \\
\hline Abebe F et al (18) & 2012 & Ethiopia & $\begin{array}{l}\text { Health facility \& community } \\
\text { based case control }\end{array}$ & 324 \\
\hline Amano A et al (19) & 2012 & Ethiopia & Community based cross sectional & 855 \\
\hline Anyait A et al (20) & 2012 & Uganda & Community based cross sectional & 500 \\
\hline Teferra AS et al (21) & 2012 & Ethiopia & Community based cross sectional & 371 \\
\hline $\begin{array}{l}\text { Kabakyenga JK et al } \\
\text { (22) }\end{array}$ & 2012 & Uganda & Community based survey & 759 \\
\hline Mekonnen MG et al (23) & 2012 & Ethiopia & Community based survey & 7978 \\
\hline Fikre AA et al (24) & 2012 & Ethiopia & Community based cross sectional & 506 \\
\hline Dhakal S et al (25) & 2011 & Nepal & Community based cross sectional & 150 \\
\hline Wanjira C et al (26) & 2011 & Kenya & Hospital based cross sectional & 409 \\
\hline Abera M et al (27) & 2011 & Ethiopia & Community based cross sectional & 1074 \\
\hline Oguntunde O et al (28) & 2010 & Nigeria & Community based cross sectional & 332 \\
\hline Babalola S et al (29) & 2009 & Nigeria & Community based survey & 2158 \\
\hline Thind A et al (30) & 2008 & India & Community based cross sectional & 5391 \\
\hline Hounton S et al (31) & 2008 & $\begin{array}{l}\text { Burkina } \\
\text { Faso }\end{array}$ & Community based cross sectional & 81,536 \\
\hline $\begin{array}{l}\text { Mpembeni RNM et al } \\
\text { (32) }\end{array}$ & 2007 & Tanzania & Community based cross sectional & 974 \\
\hline Idris SH et al (33) & 2006 & Nigeria & Community based cross sectional & 496 \\
\hline Wagle RR et al (34) & 2004 & Nepal & Community based cross sectional & 308 \\
\hline Mekonnen Y et al (35) & 2003 & Ethiopia & Community based cross sectional & 478 \\
\hline & & & & \\
\hline
\end{tabular}

\section{Methodological quality of the included studies}

As recommended by Cochrane collaboration, Evers checklist was used to assess the methodological quality of the included studies (36). Fourteen of the nineteen items were appropriate for this study to assess the methodological quality of the included studies. All included studies described well: the study population, the objective/research question, study design, outcome measures and values and ethical issues. They have also discussed the limitations and generalizability of the findings of the study. Their conclusions were based on their results. However, there was marked variation in their sample size. The extremely low and high sample sizes were 150 and 81,536, respectively. The remaining studies used sample sizes ranging from 324 to 7978 .

\section{Findings of the review}

This meta-analysis demonstrated that maternal age was not a predictor of birth in the health facility (Figure 2). However, in four of the studies $(18,19$, $31,34)$, the chance of delivering in health facilities was about 1.7-to 3.4-times higher in teenagers than in older women. Only one study (26) showed statistically significant association of home delivery among adult women. The chance of adult women giving birth in the health facility was by about $72 \%$ less than teenage women. 
was about 5.7-fold among women educated to secondary and above level $(\mathrm{OR}=5.7 ; 95 \% \mathrm{CI}$, 3.77-8.60) and about 3.9-fold among secondary and above level educated husbands $(\mathrm{OR}=3.9$; $95 \%$ CI, 2.80 - 8.60). As the overall OR showed, the chance of delivering in health facilities among educated couples was 5-fold higher than less

$$
\text { Odds Ratio }
$$

Study or Subgroup

$\mathrm{M}-\mathrm{H}$, Random, $95 \% \mathrm{Cl}$

2.1.1 Maternal education

Mpembeni RNM et al 2007

Idris $\mathrm{SH}$ et al 2006

Shiferaw S et al 2013

Anyait A et al 2012

Wado YD et al 2013

Kabakyenga JK et al 2012

Worku AG et al 2013

Fikre AA et al 2012

Amano A et al 2012

Thind A et al 2008

Wanjira C et al 2011

Mekonnen MG et al 2012

Tsegay $Y$ et al 2013

Abera M et al 2011

Babalola S et al 2009

Wagle RR et al 2004

Dhakal S et al 2011

Hounton S et al 2008

Mengesha ZB et al 2013

Abebe F et al 2012

Teferra AS et al 2012

Mekonnen Y et al 2003

Subtotal $(95 \% \mathrm{CI})$

Total events

Heterogeneity: $\mathrm{Tau}^{2}=0.89 ; \mathrm{Chi}^{2}=499.83, \mathrm{df}=21(\mathrm{P}<0.00001) ; \mathrm{I}^{2}=96 \%$

Test for overall effect: $Z=8.26(P<0.00001)$

2.1.2 Paternal education

Anyait A et al 2012

Idris SH et al 2006

Nanjala M et al 2012

Worku AG et al 2013

Thind A et al 2008

Dhakal S et al 2011

Mekonnen MG et al 2012

Amano A et al 2012

Wagle RR et al 2004

Mengesha ZB et al 2013

Abebe $\mathrm{F}$ et al 2012

Subtotal $(95 \% \mathrm{Cl})$

Total events

Heterogeneity: $\mathrm{Tau}^{2}=0.23 ; \mathrm{Chi}^{2}=59.49, \mathrm{df}=10(\mathrm{P}<0.00001) ; \mathrm{I}^{2}=83 \%$

Test for overall effect: $Z=8.29(P<0.00001)$

Total $(95 \% \mathrm{Cl})$

$5.01[3.68,6.82]$

Total events

Heterogeneity: $\mathrm{Tau}^{2}=0.73 ; \mathrm{Chi}^{2}=616.15, \mathrm{df}=32(\mathrm{P}<0.00001) ; \mathrm{I}^{2}=95 \%$

Test for overall effect: $Z=10.27(P<0.00001)$

Test for subaroup differences: $\mathrm{Chi}^{2}=2.17, \mathrm{df}=1(\mathrm{P}=0.14), \mathrm{I}^{2}=53.9 \%$ educated counterparts $(\mathrm{OR}=5.0 ; 95 \% \mathrm{CI}, 3.68$ 6.82). The heterogeneity testing still revealed significant variability $\left(\mathrm{I}^{2}=95 \%\right)$. The sensitivity analysis (with the exclusion of any of the included studies), however, revealed the stability of both the subgroup and the overall ORs.

Figure 4: Odds ratio of women's health facility delivery from a subgroup analysis by level of parents' education, primary or no education vs secondary and above 
Figure 5 shows the association of birth in the health facility with their wealth status. In two studies $(16,26)$, delivering in health facility was not associated with wealth status. In other included studies, however, women with middle to highest wealth status were about 2 to 5 times more likely to deliver in health facilities as compared to the women with low or lowest wealth status. As a result, the pooled effect showed statistically significant association of birth in the health facility with middle to highest wealth status $(\mathrm{OR}=$ 2.3 ; 95\% CI, 1.61 - 3.19). In the sensitivity analysis, the overall OR continued to be in the significant range. Heterogeneity testing revealed significant variability among the included studies $\left(\mathrm{I}^{2}=91 \%\right)$.

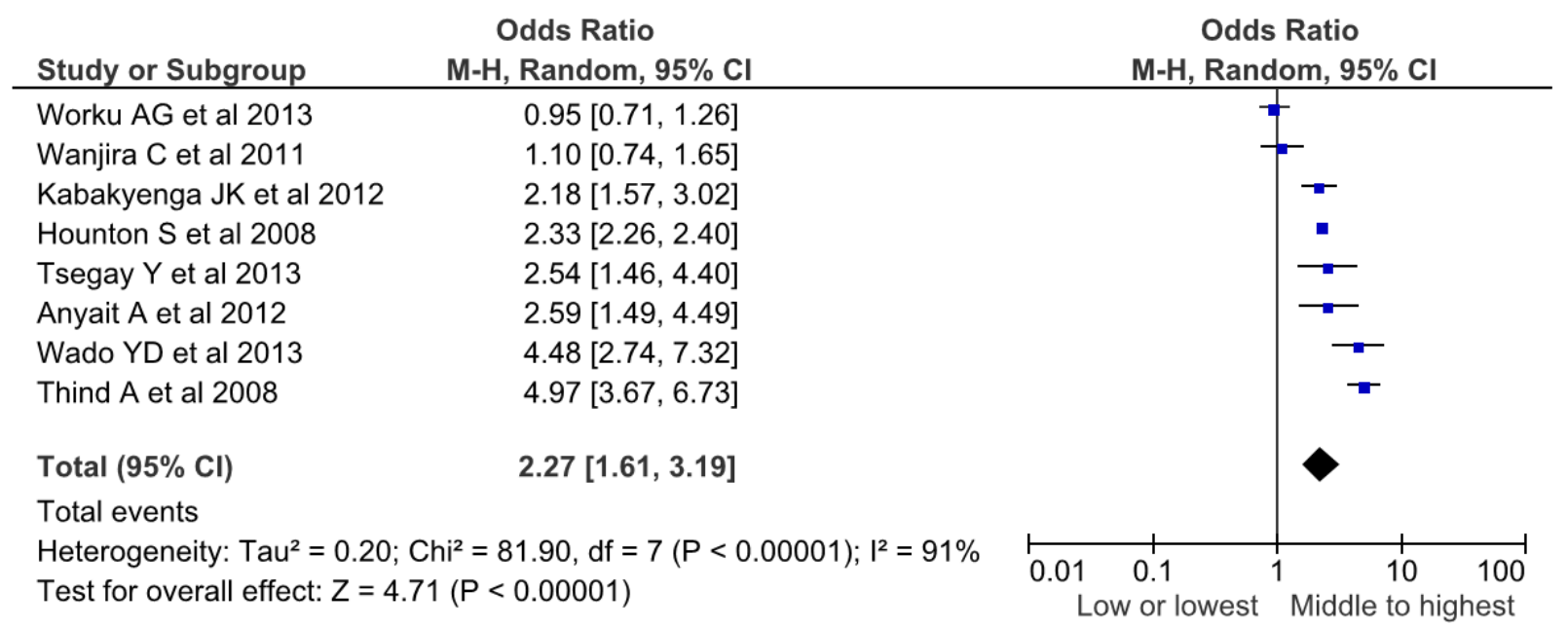

Figure 5: Odds ratio of women's health facility delivery by their wealth status, low or lowest vs middle to highest

As shown in Figure 6, in three studies $(15,32,35)$, the chance of unmarried women's health facility delivery was about $71 \%, 38 \%$ and $59 \%$ less than married women. However, the overall OR did not demonstrate a statistically significant association of birth in the health facility with marital status. It was noted that with the exclusion of Anyait A et al study (20), unmarried women were less likely to deliver in a health facility $(\mathrm{OR}=0.6 ; 95 \% \mathrm{CI}$, 0.37 - 0.94).

Odds Ratio

Odds Ratio

Study or Subgroup

M-H, Random, $95 \% \mathrm{Cl}$

M-H, Random, 95\% Cl

\begin{tabular}{|c|c|c|c|}
\hline Mengesha ZB et al 2013 & $0.29[0.18,0.46]$ & 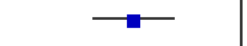 & \\
\hline Mekonnen Y et al 2003 & $0.41[0.32,0.52]$ & - & \\
\hline Mpembeni RNM et al 2007 & $0.62[0.46,0.84]$ & $\rightarrow-$ & \\
\hline Tsegay Y et al 2013 & $1.06[0.41,2.73]$ & & \\
\hline Kabakyenga JK et al 2012 & $1.51[0.77,2.94]$ & & \\
\hline Anyait A et al 2012 & $1.57[0.83,2.97]$ & & \\
\hline Total $(95 \% \mathrm{Cl})$ & $0.70[0.43,1.14]$ & & \\
\hline \multicolumn{4}{|c|}{ Total events } \\
\hline \multicolumn{2}{|c|}{$\begin{array}{l}\text { Heterogeneity: } \mathrm{Tau}^{2}=0.29 ; \mathrm{Chi}^{2}=35.20, \mathrm{df}=5(P<0.00001) ; \mathrm{I}^{2}=86 \% \\
\text { Test for overall effect: } Z=1.44(P=0.15)\end{array}$} & 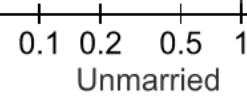 & $\begin{array}{lll}2 & 5 & 10 \\
\text { Married } & \end{array}$ \\
\hline
\end{tabular}

Figure 6: Odds ratio of women's health facility delivery by marital status, married vs unmarried (single, divorced, widowed) 
With regard to parity, however, primigravid women (being pregnant for the first time) were more likely to deliver in health facilities than multiparous women $(\mathrm{OR}=2.8 ; 95 \% \mathrm{CI}, 2.16$ $3.70)$. In two studies $(23,28)$, health facility delivery was not associated with parity. The sensitivity analysis attested the stability of the overall OR and the heterogeneity testing showed the presence of moderate variability among the included studies $\left(\mathrm{I}^{2}=54 \%\right)$.
Odds Ratio

Study or Subgroup

Oguntunde O et al 2010

Mekonnen MG et al 2012

Teferra AS et al 2012

Amano A et al 2012

Mengesha ZB et al 2013

Wagle RR et al 2004

Abera M et al 2011

Total $(95 \% \mathrm{CI})$

Total events

Heterogeneity: $\mathrm{Tau}^{2}=0.07 ; \mathrm{Chi}^{2}=13.04, \mathrm{df}=6(\mathrm{P}=0.04) ; \mathrm{I}^{2}=54 \%$

Test for overall effect: $Z=7.55(P<0.00001)$
Odds Ratio $\mathrm{M}-\mathrm{H}$, Random, $95 \% \mathrm{Cl}$

$1.02[0.43,2.44]$

$1.67[0.96,2.91]$

$2.84[1.44,5.60]$

$3.11[1.97,4.90]$

$3.24[2.32,4.53]$

$3.67[2.28,5.91]$

$3.81[2.72,5.33]$

$2.83[2.16,3.70]$

Figure 7: Odds ratio of women's health facility delivery by parity, primigravida vs multiparous

Although the data were unfit for meta-analysis (because of variation in data grouping among primary studies), correlation analysis demonstrated an inverse relationship between distance from the nearby health facility and proportion of health facility delivery $(11,18,19$, $21,30,31,33)$.

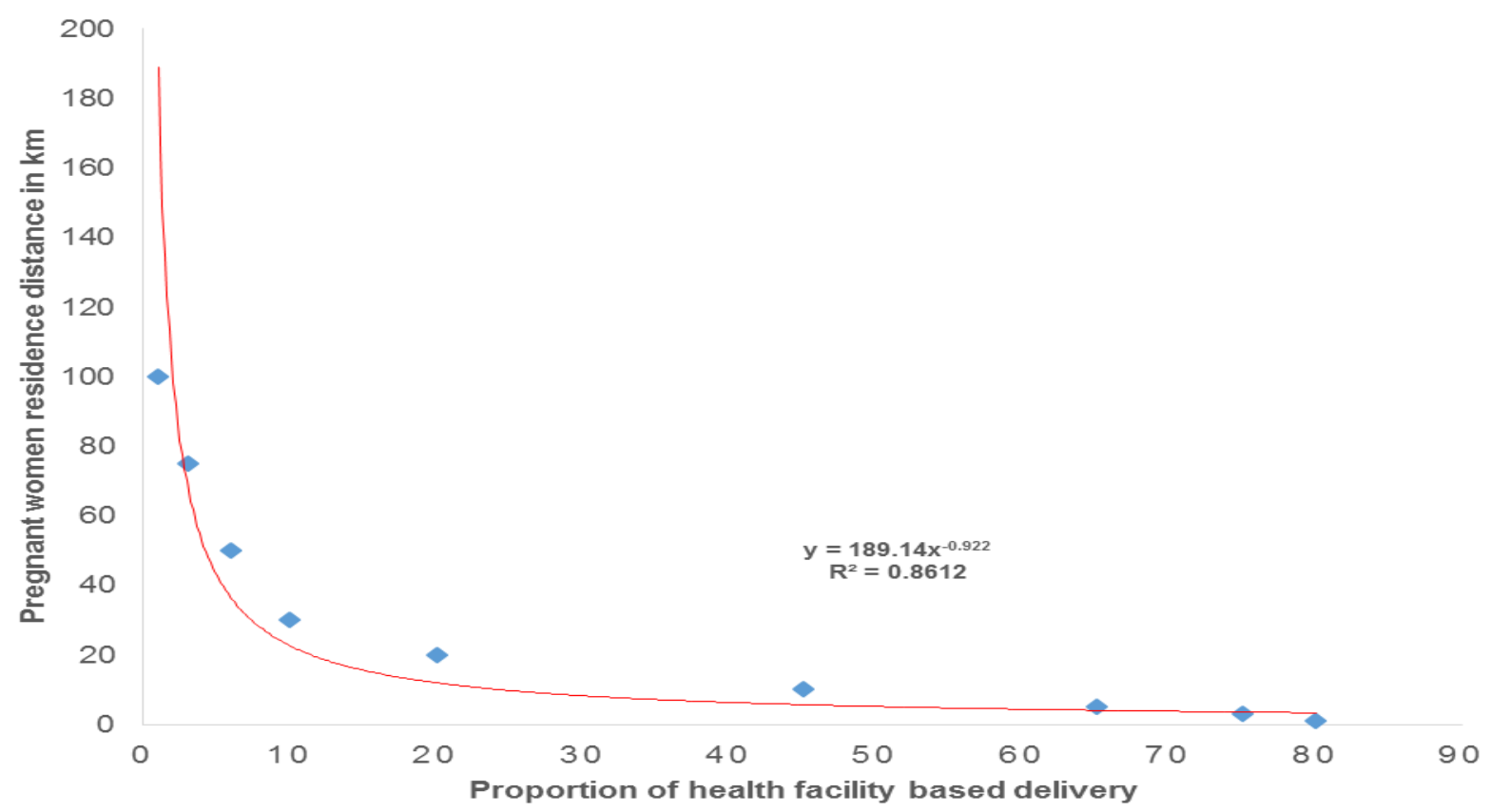

Figure 8: The correlation of distance from the nearby health facility with proportion of birth in the health facility 


\section{DISCUSSION}

The present meta-analysis demonstrated increased birth in health facility among educated women, women having educated husbands, primigravid women, wealthy women and women living in urban areas. Although several variables which were associated with an increase in health facility delivery were identified, mothers' residential area was a very strong predictor. Nevertheless, secondary and above educational level of pregnant women and of their husbands seems easily amenable to intervention.

The finding of strong association of birth in the health facility with increased level of education is consistent with the findings of several other studies not included in this meta-analysis (7, $37,38)$. The importance of education in maternal health service utilization and reduction of mortality was also noted in other reviews $(39,40)$.

Specific to Ethiopia, from where twelve of the twenty-four selected studies were reported, the message of this meta-analysis is a lot to work more on public education. Furthermore, the extremely low proportion of health facility delivery (6\%-10\%) during the last decade (41) was probably because of the low proportion of adult literacy rate (39\%) in Ethiopia (1).

We also infer that the significant association of health facility delivery with primigravid and teenage (in some studies) may still strengthen the importance of education as the majority of the young women in the last decade have got the chance of formal education in several developing countries $(42,43)$. The strong association of health facility delivery with parity is consistent with our day-to-day observations in the clinical practice. Couples and family members are usually observed giving more care for first time planned pregnancies.

On the contrary, low utilization of maternal health services by the parous women is a commonly observed phenomenon. A previous study showed that being pregnant for the first time was a strong predictor for maternal health service utilization (44). Another study also showed the negative association of health facility delivery with parity (45). However, it should be noted that a study from Botswana reported the association of low parity with low health facility delivery (7).

In the meta-analysis, residential area was the predictor with the largest effect size (OR) of place of birth. This much high association of health facility delivery in pregnant women coming from urban areas may still be linked to their level of education and wealth status. This is because, it is expected that living in urban areas is an advantage for the majority to have formal education, better wealth and living standard, better access to mass media and other sources, which all are likely to increase their awareness about the importance of maternal health service utilization and their freedom of making decision in terms of expenses (46).

However, it is also imperative to see the other side of the coin. Living in the rural area is living in the disadvantaged zone for transport and access to health facilities particularly in developing countries where infrastructures are not yet well established. It has been also observed that there was an inverse relation of distance from the nearest health facility with the proportion of health facility delivery. Several other studies have also identified lack of geographic access to emergency obstetric care as a key factor for most rural women to deliver at home without skilled care and to have high maternal and perinatal mortality (47-51).

In this meta-analysis, the statistically significant association of delivery in the health facility with middle to highest wealth status may indicate their economic capability to afford the health service costs. It is also expected that the majority of couples who are able to afford these types of costs are somehow educated and live in urban areas, and may have better awareness on birth preparedness and complication readiness (44).

This meta-analysis is not without limitations. Since the majority of the included studies were from Ethiopia, the findings may not be generalized to all developing countries. Due to lack or inconsistency of data grouping in the primary studies, several other quantitatively collected variables (like religion, occupation, polygyny, own radio/TV, birth order, knowledge about danger symptoms of pregnancy, discussion on the place of delivery and distance to the nearest health facility) that may determine the place of delivery were not meta-analyzed.

In conclusion, lack of health facility delivery is one of the major problems impeding the achievement of the MDG 4 and 5 in several 
developing countries. The present meta-analysis gave insight into some factors contributing to failure to utilize health facility delivery services (low educational level of women and their husbands, living in a rural area, having low or the lowest wealth index and being multiparous). Directly or indirectly, educational level and wealth status of the couple have contributed much to the low delivery in the health facility. There are also other several works which support this statement (52-54). Therefore, to increase the proportion of health facility delivery in the studied areas, a lot has to be done to increase the educational level of parents to be in the near future and wealth status in the long term. Furthermore, why multiparous women take more risk by delivering outside health facilities is an area of investigation.

\section{ACKNOWLEDGEMENT}

We would like to thank PANE and KMG Ethiopia for the modest financial support granted for this review. We are also grateful to UNFPA Ethiopia for their generous financial support to cover the publication fee.

\section{REFERENCES}

1. World health organization (WHO). World Health Statistics 2013. Last accessed in August 2013: www.who.int/entity/gho/

2. WHO, UNICEF, UNFPA and The World Bank estimates. Trends in Maternal Mortality: 1990 to 2010. http://whqlibdoc.who.int/publications/pdf

3. World Health Organization. Neonatal and perinatal mortality: country, regional \& global estimates. Geneva, Switzerland, 2006. whqlibdoc.who.int/publications/pdf.

4. Hussein J, Bell J, Nazzar A, Abbey M, Adjei S, Graham W. The skilled attendance index: proposal for a new measure of skilled attendance at delivery. Reprod Health Matters 2004; 12:160-70.

5. World Health Organization. Maternal mortality. Fact sheet number 348. 2012. http://www.who.int/mediacentre/

6. Seljeskog L, Sundby J, Chimango J. Factors influencing women's choice of place of delivery in rural Malawi - An exploratory study. Afr J Reprod Health 2006; 10(3): 6675.

7. Letamo G, Rakgoasi SD. Factors Associated with Non-use of Maternal Health Services in Botswana. J Health Popul Nutr 2003; 21(1):40-47.

8. Parkhurst JO, Rahman SA, Ssengooba F. Overcoming Access Barriers for Facilitybased Delivery in Low-income Settings: Insights from Bangladesh and Uganda. $J$ Health Popul Nutr 2006; 24(4):438-445.

9. Gage AJ. Barriers to the utilization of maternal health care in rural Mali. Soc Sci Med 2007; 65(8):1666-82.

10. Zere E, Oluwole D, Kirigia JM, Mwikisa CN, Mbeeli $\mathrm{T}$. Inequities in skilled attendance at birth in Namibia: A decomposition analysis. BMC Pregnancy and Childbirth 2011, 11:34. http://www.biomedcentral.com/

11. Wado YD, Afework MF, Hindin MJ. Unintended pregnancies and the use of maternal health services in southwestern Et hiopia. BMC Int Health Hum Rights 2013; 13:36. doi: 10.1186/1472-698X-13-36.

12. Shiferaw S, Spigt M, Godefrooij M, Melkamu Y, Tekie M. Why do women prefer home births in Ethiopia? BMC Pregnancy Childbirth 2013; 13:5. doi: 10.1186/14712393-13-5.

13. Tsegay Y, Gebrehiwot T, Goicolea I, Edin K, Lemma H, Sebastian $\quad$ MS. Determinants of antenatal and delivery care ut ilization in Tigray region, Ethiopia: a crosssectional study. Int J Equity Health 2013; 12:30. doi: 10.1186/1475-9276-12-30.

14. Mengesha ZB, Biks GA, Ayele TA, Tessema GA, Koye DN. Determinants of skilled attendance for delivery in Northwest Ethiopia: a community based nested case control study. BMC Public Health 2013; 13:130. doi: 10.1186/1471-2458-13-130.

15. Worku AG, Yalew AW, Afework MF. Factors affecting utilization of skilled maternal care in Northwest Ethiopia: a multilevel analysis. BMC Int Health Hum Rights 2013; 13:20. doi: 10.1186/1472-698X-13-20.

16. Nanjala M, Wamalwa D. Determinants of male partner involvement in promoting deliveries by skilled attendants in Busia, Kenya. Glob $J$ 
Health Sci 2012; 4(2):60-7. doi: 10.5539/gjhs.v4n2p60.

17. Abebe F, Berhane Factors associated Y, Girma B. with home delivery in Bahirdar, Ethiopia: a case control study. BMC Res Notes 2012; 5:653. doi: 10.1186/1756-0500-5-653.

18. Amano A, Gebeyehu A, Birhanu Z. Institutional delivery service utilization in Munisa Woreda, South East Ethiopia:a com munity based cross-sectional study. BMC Pregnancy Childbirth 2012; 12:105. doi: 10.1186/1471-2393-12-105.

19. Anyait A, Mukanga D, Oundo GB, Nuwaha F. Predictors for health facility delivery in Busia district of Uganda:

a cross sectional study. BMC Pregnancy Childbirth 2012; 12:132. doi: 10.1186/14712393-12-132.

20. Teferra AS, Alemu FM, Woldeyohannes SM. Institutional delivery service utilization and associated factors among moth ers who gave birth in the last 12 months in Sekela District, North West of Ethiopia: a community-based cross sectional study.

BMC Pregnancy Childbirth 2012; 12:74. http://www.biomedcentral.com/

21. Kabakyenga JK, O stergren P-O, Turyakira E, Pettersson KO. Influence of Birth Preparedness, Decision-Making on Location of Birth and Assistance by Skilled Birth Attendants among Women in South-Western Uganda. PLoS ONE 2012; 7(4): e35747. doi:10.1371/journal.pone.0035747.

22. Mekonnen MG, Yalew KN, Umer JY, Melese M. Determinants of delivery practices among Afar pastoralists of Ethiopia. Pan Afr Med J 2012;13 Suppl 1:17.

23. Fikre AA, Demissie M. Prevalence of institutional delivery and associated factors in Dodota Woreda (district), Oromia regional state, Ethiopia. Reprod Health 2012; 9:33. doi: 10.1186/1742-4755-9-33.

24. Dhakal S, van Teijlingen E, Raja EA, Dhakal KB. Skilled care at birth among rural women in Nepal: practice and challenges J Health Popul Nutr 2011; 29(4):371-8.

25. Wanjira $C$, Mwangi M, Mathenge E, Mbugua G, Ng'ang'a Z. Delivery practice and associated factors among mothers seeking chil $\mathrm{d}$ welfare services in selected healthfacilities $\mathrm{i}$ n Nyandarua South District, Kenya. $\quad B M C$ Public Health 2011; $\quad 11: 360 . \quad$ doi: 10.1186/1471-2458-11-360.

26. Abera M, G/Mariam A, Belachew T. Predictors of safe delivery service utilization in Arsi Zone, South-East Ethiopia. Ethiop J Health Sci 2011; special issue. 101-113.

27. Oguntunde O, Aina O, Ibrahim MS, Umar HS, Passano P. Antenatal Care and Skilled Birth Attendance in Three Communities in Kaduna State, Nigeria. Afr J Reprod Health 2010; 14(3): 89-96.

28. Babalola S, Fatusi A. Determinants of use of maternal health services in Nigeria--

looking beyond individual and household fact ors. BMC Pregnancy Childbirth 2009; 9:43. doi: 10.1186/1471-2393-9-43.

29. Thind A, Mohani A, Banerjee K, Hagigi F. Where to deliver? Analysis of choice of delivery location from

a national survey in India. BMC Public Health 2008; 8:29. doi: 10.1186/1471-2458-829.

30. Hounton S, Chapman G, Menten J, et al. Accessibility and utilisation of delivery care within a Skilled Care Initiative in rural Burkina Faso. Trop Med Int Health 2008; 13 (Suppl 1):44-52.

31. Mpembeni RN, Killewo JZ, Leshabari MT, et al. Use pattern of maternal health services and determinants skilled care during delivery in Southern Tanza nia: implications for achievement of MDG5 targets. BMC Pregnancy Childbirth 2007; 7:29. http://www.biomedcentral.com

32. Idris SH, Gwarzo UMD, Shehu AU. Determinants of place of delivery among women in a semi-urban settlement in Zaria, Northern Nigeria. Annals of African Medicine 2006; 5(2): 68-72.

33. Wagle RR, Sabroe S, Nielsen BB. Socioeconomic and physical distance to the maternity hospital as predictors for place of de livery: an observation study from Nepal. $B M C$ Pregnancy $\quad$ Childbirth 2004; 4(1):8. http://www.biomedcentral.com

34. Mekonnen Y, Mekonnen A. Factors influencing the use of maternal health services in Ethiopia. J Health_Popul Nutr 2003; 21(4):374-82. 
35. Parkhurst JO, Ssengooba F. Assessing access barriers to maternal health care: measuring bypassing to identify health centre needs in rural Uganda. Health Policy Plan 2009; 24:377-384.

36. The Cochrane collaboration. Cochrane Handbook for Systematic Reviews of Interventions version 5.1.0 (2011). http://handbook.cochrane.org/

37. Lwelamira J, Safari J. Choice of Place for Childbirth: Prevalence and Determinants of Health Facility Delivery among Women in Bahi District, Central Tanzania. AJMS 2012; 4(3): 105-112.

38. Kitui J, Lewis S, Gail Davey. Factors influencing place of delivery for women in Kenya: an analysis of the Kenya demographic and health survey, 2008/2009. BMC Pregnancy and Childbirth 2013, 13:40. http://www.biomedcentral.com/

39. Berhan Y, Berhan A. Antenatal Care as a means of increasing birth in the health facility and reducing maternal mortality: a systematic review. Ethiop J Health Sci 2014. Special issue 1.

40. Berhan Y, Berhan A. Reasons for persistently high maternal and perinatal mortalities in Ethiopia: Part II - Socio-economic and cultural factors. Ethiop J Health Sci 2014. Special issue 1 .

41. Central Statistical Agency [Ethiopia] and ICF International. 2012. Ethiopia Demographic and Health Survey 2011. Addis Ababa, Ethiopia and Calverton, Maryland, USA: Central Statistical Agency and ICF International.

42. The William and Flora HEWLETT Foundation. Quality education in developing countries.

http://www.hewlett.org/programs/globaldevelopment-and-population-program/qualityeducation.

43. The Center for Global Development. Education and the developing world. http://www.cgdev.org/files/2844_file_EDUC ATON1.pdf.

44. Hailu M, Gebremariam A, Alemseged F, Deribe K. Birth Preparedness and Complication Readiness among Pregnant
Women in Southern Ethiopia. PLoS ONE 2011; 6(6): e21432. doi:10.1371/journal.pone.0021432

45. Bhatia JC, Cleland J. Determinants of maternal care in a region of South India. Health transition review 1995; 5: 127-42.

46. UNFPA. State of World Population. Condition of life in urban population. Last accessed June 2014 from: http://www.unfpa.org/swp/1996/ch2.htm.

47. Thaddeus S, Maine D. Too far to walk: Maternal mortality in context. Soc Sci Med 1994; 38: 1091-1110.

48. Gabrysch S, Campbell OM. Still too far to walk: Literature review of the determinants of delivery service use. BMC Pregnancy Childbirth 2009; 2 9: 34. http://www.biomedcentral.com

49. Gabrysch S, Cousens S, Cox J, Campbell OMR. The Influence of Distance and Level of Care on Delivery Place in Rural Zambia: A Study of Linked National Data in a geographic Information System. PLoS Med 2011; 8(1): e1000394. doi:10.1371/journal.pmed.1000394

50. Hodgkin D. Household characteristics affecting where mothers deliver in rural Kenya. Health Econ 1996; 5(4):333-40.

51. Rockers PC, Wilson ML, Mbaruku G, Kruk ME. Source of antenatal care influences facility delivery in rural Tanzania: a population-based study. Matern Child Health $J$ 2009; 13(6):879-85.

52. Wilde J. Health Impacts of Education: a review. Institute of Public Health in Ireland 2008. www.publichealth.ie

53. Vora KS, Mavalankar DV, Ramani KV, Upadhyaya M, Sharma B, Iyengar S, Gupta V, Iyengar K. Maternal health situation in India:

a case study. J Health Popul Nutr 2009; 27(2):184-201.

54. Tarekegn SM, Lieberman LS, Giedraitis V. Determinants of_maternal health service utilization in Ethiopia: analysis of the 2011 Ethiopian Demographic and_Health_Survey. $\quad B M C \quad$ Pregnancy Childbirth 2014 May 7;14:161. doi: 10.1186/1471-2393-14-161. 